\title{
Perceived Social Support and Self-Esteem towards Gender Roles: Contributing Factors in Adolescents
}

\author{
Cai-Lian Tam \\ Jeffery Cheah School of Medicine and Health Sciences \\ Monash University Sunway Campus, Malaysia \\ E-mail: tam.cai.lian@monash.edu.my \\ Teck-Heang Lee (Corresponding author) \\ School of Business \\ Monash University Sunway Campus, Malaysia \\ E-mail: lee.teck.heang@buseco.monash.edu.my \\ Wai-Mun Har \\ Faculty of Accountancy \& Management \\ Universiti Tunku Abdul Rahman, Malaysia \\ E-mail: harwn@mail.utar.edu.my \\ Wei-Li Pook \\ Faculty of Creative Industry \\ Universiti Tunku Abdul Rahman, Malaysia \\ E-mail: pookwl@gmail.com
}

Received: February 16, $2011 \quad$ Accepted: March 23, $2011 \quad$ doi:10.5539/ass.v7n8p49

\begin{abstract}
The study aims to examine the relationship between self-esteem and perceived social support among the Malaysian adolescents. Gender differences of perceived social support and self-esteem among the respondents were also investigated. To achieve the objectives of the study, a survey was conducted with a relatively large $(n=460)$ random samples of adolescents, aged 16-20, drawn from schools, colleges and universities in Malaysia. The Self-esteem Rating Scale (SERS) and the Multidimensional Scale of Perceived Social Support (MSPSS) were used in the study. The results indicated that there were no gender differences in perceived social support and self-esteem among adolescents. However, a positive correlation was found between perceived social support and self-esteem. The study also found peer support was the highest form of perceived social support.
\end{abstract}

Keywords: Adolescents, Perceived social support, Self-esteem, Gender differences

\section{Introduction}

Adolescence is described as a transitional period in which individual experience major physical, cognitive, and socio affective changes (Dumont \& Provost, 1999). According to Frechette and LeBlane (1987), a vast majority of adolescents range from 12 to 18 years old have committed in delinquent behavior. Frechette and LeBlane revealed that $92.8 \%$ of the adolescents recognized that they have involved in the delinquent activities for at least one, more or less during their adolescence hood. It is plausible to believe that the increasing rate for the delinquent behavior will potentially lead to serious social problems. Hence, it should be given a due concern as it would likely to impede the development of nations in a holistic manner (Cartwright, 2000, Riecken \& Yavas, 2001). 
In Malaysia, adolescents' delinquent behavior has been on the rise. The findings from the study of Lee, Chen, Lee and Kaur (2007) have reflected the problem of youth crime in Malaysia as the study showed that $55 \%$ of the students had their property stolen, $27.9 \%$ involved in physical fight, $18.5 \%$ had their money stolen, $7.2 \%$ had felt unsafe and 5.9\% had carried weapon. In addition, the Royal Malaysian Police (2004) reported that there were 14,691 juveniles arrested through the year of 2002 till 2004. Ranked the highest (63\%) offenses are crime related to property. While the second highest (5.3\%) were offences affecting human body. Therefore, Malaysian adolescent violence can be witnessed as a serious social issue which needs to be addressed in order to attain balanced development as the long-term targets.

There are specific evidences that revealed a relationship between self-esteem and violence. For instance, Corwyn and Benda (2001) reported a significant relationship between low self-esteem and violent behavior among adolescents aged 13-15. In line with the findings of Corwyn and Benda (2001), the results of Hollister-Wagner, Foshee and Jacson (2001) showed that adolescents with high self-esteem are more likely to act on their beliefs and protect the victims. Therefore, it is essential to explore the conventional wisdom of self-esteem as most of the research evidences revealed low self-esteem as the powerful predictor for adolescents' delinquency.

Besides, developing understanding of the potential buffering effect of social support which includes family and peer support is particularly important as some evidences found social support may well buffer the relationship between violence and psychological distress (Herman-Stahl \& Pertersen, 1996). Hence, having social support network can lead to positive health outcomes. On the other hand, lack of social support will in turn create unhealthy state and delinquent behavior (Cohen \& Wills, 1985). All in all, self-esteem and perceived social support have been recognized as the major predictor factors that correlate significantly to various forms of regressive behavior and adjustment of the adolescents (Geuzaine, Debry \& Liesens, 2000; Mizell, 1999). In addition, studies (e.g. Chubb, Fertman \& Ross, 1997; Dumont \& Provost, 1999; Colarossi, 2001) found that gender is an important area of study in perceived of support from various constructs because gender differences may affect outcomes which may also serve as a protective factor for the problems of adolescence.

Through this study, we attempt to explore how perceived social support factors would affect an individual's self-esteem levels. The contribution of conducting such a research is to enable mental health professionals to better pin point their efforts in improving society's self-esteem and perceived social support. Researching on the relationship between self-esteem and perceived social support factors would also allow mental health professionals, parents and educators to plan intervention techniques to help respondents with lower level of self-esteem. This is crucial for the development of an individual as self-esteem has been found to have protective effect against discrimination and lead to better mental health (Fischer \& Shaw, 1999).

To conclude, the objective of the study is to examine the relationship between self-esteem and perceived social support. It also aims to investigate gender differences of perceived social support and self-esteem among the Malaysian adolescents. It is hoped that a comprehensive understanding of such relationship will in turn provide effective means in mitigating the present rise in youth crime in Malaysia.

\section{Literature Review and Hypotheses Development}

This section aims to outline the definition of the research variables and discuss their research evidences. At the end of the section, hypotheses of the study are developed based on the review of the literature.

\subsection{Definition of Social Support}

Section 2.1 highlights several definitions of social support. For example, Dumont and Provost (1999) defined social support as a multidimensional concept which includes support received from friends, family, strangers, and animals. This support can be further classified into information, emotion and instrument. Another definition by Colarossi (2001) showed that social support is a multifaceted construct. Colarassi explained that such construct includes disaggregation and specification across structural and functional dimensions. On the other hand, Farmer and Farmer (1996) contended that social support is a process of social change that contributes to the development of a person for his/her values, behavioral pattern and social cognitive. In sum, social support can be viewed as care, value and guidance provided from family, peer and community members (Dollete, Steese, Philips, \& Matthews, 2006).

\subsection{Definition of Self-Esteem}

Harter (1990) described self-esteem as how one likes, accepts, and respects oneself as a person. Harter asserted that there are two different theoretical views of self-esteem; namely, (i) how a person perceived success with reference to the importance of success in that particular domain; and (ii) how a person perceives himself/herself which is originating from him/her own perceptions. In another perspective, Freshbach and Weiner (1991) 
claimed that self-esteem is a positive or negative value based on one's own attributes. In a nutshell, self-esteem is how an individual feels about himself or herself.

\subsection{Research Evidences of Perceived Social Support and Self-esteem}

Kaplan (1980) argued that there is a strong relationship between low self-esteem and delinquent behavior. He found that individuals who were unsuccessful for example, getting bad examination results and failing to get along with peers are likely to suffer from low self-esteem. Many of these adolescents tend to respond to such feeling of low self-esteem through delinquent behavior. Providing adequate social support may seen to be a remedial action as indicated in various studies found in Moradi and Funderbunk (2006). In addition, Lipschitz-Elhawi and Ltzhaky (2005), Teoh and Nur Afiqah (2010) showed a positive relationship between perceived social support and self-esteem.

Harter (1990) claimed that one may perceive to attain support in two ways; namely, emotional support and social approval gains from others which in turn may influence an adolescent's self-esteem. Besides, the study of Brage and Meredith (1994) cited in Colarossi and Eccles (2000) reported that family support provide the strongest impacts on self-esteem. In a similar vein, Demo, Small and Savin-Williams (cited in Colarossi, 2001) found that self-esteem of an adolescent's is positively influenced by the perceptions of parental support, participation, and communication. Lakey and Cassidy (1990) cited in Moradi and Funderbunk (2006) added that people with low self-esteem often perceive lower social support. Likewise, Meehan, Durlak and Bryant (1993) cited in Moradi and Funderbunk (2006) suggested that high self-esteem will have higher perceived social support.

Huurre (2000) conducted a study on 115 adolescents. His study found that adolescents who gain high levels of social supports from their parents and peers tend to have higher self-esteem. As a result, these adolescents are less likely to suffer from the symptoms of depression. Using a younger age sample groups, the study of Parker and Asher (1987) and Wolchik, Reuhlman, Braver and Sandler (1989) also found similar results where children perceived lower level of social support from their classmates are more likely to have higher levels of depression and lower level of self-esteem.

A study conducted in Israel by Lipschitz-Elhawi and Ltzhaky (2005) using 112 adolescents to investigate the relationship between internal resources (i.e. self-esteem) and external resources (i.e. social support). The results of this study showed that peer support did not correlate with self-esteem where self-esteem is one of the adjustment scales adopted in this study. However, family supports were corresponded with self-esteem in this Israeli study.

Two Malaysian studies, among others, are found to be related in this area. They are: Teoh and Nur Afiqah (2010) and Cheng and Fatimah (n.d.). Using 200 university students, through a questionnaire survey, Teoh and Nur Afiqah (2010) examined whether personality traits and social support are associated with self-esteem. Their findings revealed that all the personality and social support factors were associated with the level of self-esteem. On the other hand, Cheng and Fatimah (n.d.) conducted a survey among 522 students from secondary schools and a local university found that there was a significant relationship between self-esteem and social support which mitigated by the functional attitude in their selected samples.

\subsection{Gender Differences in Social Support}

Social support is generally perceived differently among males and females. For example, Mahaffy (2004) found that the self-esteem of the male adolescent is higher than female adolescent. A study conducted by Colarossi (2001) to examine the gender differences in adolescents' support structure, frequency as well as satisfaction from parents, peers and other adults found similar evidences as per Mahaffy (2004). Colarossi (2001) suggested that female adolescents as compared to male adolescents are more oriented toward peers for social support and they are also more satisfied with the support gained from their peers. Besides, vast majority of them perceived women (i.e. their mother) provide them with more supports as compared to what they can obtain from men (Chun \& MacDermid 1997; Colarossi, 2001).

The findings obtained from the study of Dumont and Provost (1999) may provide an explanation that female adolescents are generally having better social networks and are more open in socializing with their peers. This is because female adolescents are more involved in nurturing, communality, and affiliation. Hence, this enables them to establish new supports more easily from outside the family context. In contrast, Hirst and DuBois (1991) found that male adolescents perceived higher level social support than their female counterparts as the males' orientation is neither bias toward peers nor adults. Therefore, the males tend to have more balance numbers of peer and adult supports. Further analysis of the results of Hirst and DuBois show that in terms of frequency, supports obtained by the male adolescents from the adults are higher as compared to the supports obtained from 
their peers. However, the male adolescents are more satisfied with the friendship support than other sources of support.

In sum, gender differences in perceived social supports can be explained by gender role expectation where males would generally prefer to communicate with women in order to gain emotional support as compared to men. It is also found that father provides higher supports to his sons than his daughters (Caldwell \& Peplau, 1982).

\subsection{Gender differences in Self-esteem}

A search in literature generally indicated that self-esteem of the male adolescents is higher than female. Studies as cited in Ayyash-Abdo (1997), for instance, Quatman and Watson (2001), and O'Brien et. al. (1996 as cited in Quatman \& Watson, 2001) reported that adolescent females obtained lower level of self-esteem as compared to adolescent males. The results also showed that although there is only a small significant difference on self-esteem between males and females, such slightly higher self-esteem obtained by the males will be beneficial to them if it persists into their adulthood.

The study of Rosenberg and Simmons (1975), and O'Malley and Bachman (1979) as found in Chubb, Fertman \& Ross (1997) showed that female adolescents reported lower level of self-esteem than male adolescents during middle and late adolescence, but not between the ages of 8 and 11. Using samples students aged 10, 12, 14, and 16, Bohan (1973, cited in Chubb, Fertman \& Ross, 1997) reported that there is generally no significant differences between ages or genders. However, differences are only found on those female students in $10^{\text {th }}$ grade where they had significantly lower level of self-esteem as compared to those younger females and the males.

According to Mahaffy (2004), the initial positive association between self-esteem in adolescence and socioeconomic achievements tend to be higher among males. This is due to the initial benefit of high self-esteem disappears for females but persists for male's occupational status and, include their earnings. Thus, Mahaffy voiced out concern that relative low self-esteem among girls compared to boys result in their lower educational and occupational achievements and subsequently, creating disadvantage in employment and income attainment among the former group.

\subsection{Hypotheses of the Study}

Based on the review of the literature in Section 2.3 - Section 2.5, the hypotheses for this research can be summarized as follows:

H1: The higher the level of perceived social support, the higher the level of self-esteem among the adolescents.

H2: There is a significant difference for perceived social support among the adolescents where females would have higher perceived social support than males.

H3: There is a significant difference for self-esteem among the adolescents where males would have higher level of self-esteem compared to females.

\section{Methodology}

\subsection{Participants}

The subjects for this research consisted of students from various secondary schools, colleges and universities around Kuala Lumpur and Petaling Jaya. Students were selected based on a convenience sample of 460 Malaysian adolescents from these targeted locations. Of the 460 students, 230 (50\%) students were male and the remaining $230(50 \%)$ were females. The genders were chosen to be equally represented on purpose, irrespective of their race and religion.

Out of the 460 students, 213 (46.3\%) of the students were Chinese, 119 (25.9\%) were Indian, and 116 (25.2\%) were Malay. The remaining 12 students $(2.6 \%)$ were of other races. They ranged in age from 13 to $22(\mathrm{M}=18.32$, $\mathrm{SD}=1.629) .145(31.5 \%)$ of them were of SPM level, 131 (28.5\%) were STPM/Pre-U/A-Levels, 95 (20.7\%) PMR level, 55 (12\%) were diploma level and 34 (7.4\%) students were of other education level.

\subsection{Procedure}

A single survey was conducted to obtain necessary results from the subjects. All students involved in this research were randomly selected and were asked whether they wished to participate in this survey. The questionnaires were given out to students who were willing to participate, together with a consent form. This consent form is not a parental consent form but only as a form of acknowledgement about the study conducted.

Ten research assistants involved in administering the process. Students who agreed to participate were given the questionnaires to complete in groups, irrespective of where they were at the time the survey was conducted. 
Initially, the nature of the study was explained to the participants before they began. It was explained to them that their answers should be their own, and they were given 40 minutes to complete the questionnaires.

\subsection{Measurement Instruments}

For the purpose of the present study, Self-esteem Rating Scale (SERS) (Nugent \& Thomas, 1992) and Social support Multidimensional Scale of Perceived Social Support (Zimet et al., 1988) were used. The SERS is a 40 -item instrument that provides a clinical measure on self-esteem. The respondents are required to rate themselves on a seven point scale (example: Never $=1$; Rarely $=2$; A little of the time $=3$; Some of the time $=4$; A good part of the time $=5$; Most of the time $=6$; and Always $=7$ ). Positive scores mean more positive self-esteem; on the other hand, negative scores indicate more negative self-esteem. SERS ensures the reliability of validity of the results as it has a high level of internal consistency (alpha of .97). It also has good content and factorial validity. Good construct validity, with significant correlations with the Index of Self-esteem and the generalized Contentment Scale is also found in this instrument.

Social support Multidimensional Scale of Perceived Social Support (MSPSS) (Zimet et al., 1988) is a 12-item instrument designed to measure perceived social support from three sources (subscales): family, friends, and a significant other. The score of MSPSS is the total of the individual item scores divided by the number of items. Higher scores reflect higher perceived social support. The MSPSS has a high level of consistency as well as good test-retest reliability. The MSPSS also has good factorial validity, concurrent validity and good construct validity.

\subsection{Data Analysis}

The study used a correlation design, examining the relationship between two variables. The first variable of the study was self-esteem, which was operationally defined by participant scores on the SERS scale, a 7-point Likert scale, consisting of 40 items ranging from never to always. The second variable tested was perceived social support which was operationally defined by the scores on the MSPSS scale, 12-item instrument designed to measure perceived social support from three sources: family, friends, and significant others.

The data collected is analyzed using an independent sample t-test to compare if there is a significant gender difference among male and female adolescents in perceived social support and self esteem towards gender roles. The relationship between perceived social support and self-esteem was explored using Pearson's product moment correlation. All data tabulations and analyses were performed using SPSS for Windows, version 15.0.

\section{Results}

\subsection{Relationship between Perceived Social Support and Self-Esteem}

It was hypothesized that the results from this study would reflect that self-esteem is positively correlated with social support. Adolescents will have greater self-esteem when they receive high social support from either family, peers, or significant others.

\section{Insert Table 1}

A bivariate correlation was conducted to investigate the relationship between perceived social support and self-esteem. Based on the Pearson's product moment correlation output, there is a positive association between self-esteem and perceived social support $[\mathrm{r}=.498, \mathrm{p}$-value $<0.01]$. This means, as perceived social support increases, self-esteem increases as well. Table 1 showed that the correlation between perceived social support and self-esteem is .498 and since $r^{2}=.248$, perceived social support may contribute approximately $24.8 \%$ to the level of self-esteem (See Table 1).

\section{Insert Table 2}

In addition, adolescents attain greater social support from friends. The result revealed that social support from friends has greater correlation with self-esteem compared to significant other and family support $[\mathrm{r}=.413$, p-value $<0.01]$. According to Table 2, the correlation between perceived social support from friends and self-esteem is .413 and $\mathrm{r}^{2}=.171$. This means that perceived social support from friends is a more significant contributory factor as compared with family and significant others. Perceived social support from friends contributes $17.1 \%$ to the development self-esteem of a person (See table 2).

\subsection{Gender Differences for Perceived Social Support and Self-Esteem}

It was hypothesized that there is gender differences in perceived social support and self-esteem between male and female adolescents. Independent sample t-tests were constructed to examine whether there are gender differences in perceived social support and self-esteem among the adolescents. 


\section{Insert Table 3}

An independent sample t-test was performed comparing the mean of male self-esteem $(\mathrm{M}=169.92, \mathrm{SD}=19.61)$, with the mean of female self-esteem $(M=175.91, S D=16.726)$. This result depicted t $(458)=.162, p=>.05$, indicating that there were no significant gender differences of self-esteem between male and female adolescents. An independent t-test was also performed comparing the mean of male social support $(\mathrm{M}=61.47, \mathrm{SD}=11.286)$, with the mean of female social support $(M=62.71, \mathrm{SD}=11.854)$. This was found to be statistically insignificant, $\mathrm{t}(458)=-1.152, \mathrm{p}=>.05$, indicating that there were no significant gender differences of social support between male and female adolescents.

\section{Discussion}

According to the results analysis obtained from this present study, we can conclude that there is a correlation amongst the two inventories used, which are Multidimensional Scale of Perceived Social Support (MSPSS) and Self-Esteem Rating Scale (SERS). This result is rather accurate as the significant level is quite high whereby there is only one percent chance that the results might have occurred by sampling error. The high reliability and good internal consistency of all two inventories used could also attribute to the accuracy of the results.

The research also aims to find out whether there is any gender difference for their perceived social support and self-esteem. Results obtained from the present study have rejected the second and third hypotheses. This implied that there was no significant difference for perceived social support and self-esteem among males and females students.

The first hypothesis was supported by the significant positive correlation between perceived social support and self-esteem. The present results are consistent with those of previous studies such as the one done by Cooper, Holman and Braithwaite (1983, cited in Dumont \& Provost, 1999). They found that teenagers' self-esteem was positively related to perceived family support. Meehan, Durlak and Bryant (1993, cited in Moradi \& Funderbunk, 2006) also found that perceived social support among high school adolescents to be correlated with self-esteem. In a similar study, Van Dras et al., (1997, cited in Dumont \& Provost, 1999) supported the significant positive correlation between perceived social support and self-esteem. They found that people with high self-esteem tend to be more gregarious and involved in more social activities, which lead to have a higher perceived social support.

The current study provides support for extending these conclusions about teenagers and school students. There are several possible explanations for this relationship between perceived social support and self-esteem in adolescents. Most Malaysian adolescents would have a higher tendency to spend their daily time with family and school. This is one of the most fundamental and central environments in their lives. Furthermore, adolescents' peer support has also been linked to important development outcomes, making it especially important to understand what factors predicting peer support as well as family support during adolescence.

There was no significant gender differences for perceived social support among male and female students, thus the second hypothesis was not supported. This outcome were identical to Vaux's (1982, 1985 as cited in Moradi $\&$ Funderbunk, 2006) research, where he found no gender differences in perceptions of support. He attributes some of this variation in gender differences in social support perceptions to differences in methods, particularly in relation to the samples and measures used.

Both results, from this present study and Vaux's (1982, 1985, as cited in Moradi \& Funderbunk, 2006) were unlike of the outcome for Colorossi's study (2001), where female adolescents perceived more supportive peers and adults, although lesser from adults. And they were satisfied with the supports they received from both peers and adults. They also reported that mothers were their most important support, as opposed to the results of this study. The possible reason for the differences in the outcomes of these studies was that it could be the different measurement scales used. Open-ended and more directive questions were asked in Colorossi's (2001) study, which may prompt more direct answers, as compared to the present study, which used the Multidimensional Scale of Perceived Social Support (MSPSS), a measurement of 5-point Likert scales. This measurement may be a constriction as students could only answer 'strongly disagree' to strongly agree' and therefore, not being able to find out what influence or contribute to the perception of perceived social support. It could also due to the different cultural aspects as these studies were conducted in the different cultural expectation.

The insignificant difference of family social support of the present study may provide an understanding that young adults in the Malaysian context would not experience much constraint in obtaining freedom from the shelter of parents as compared to during adolescence. Parents would have more trust in their children and thus, individuals in this stage of development are able to explore their independence more freely. Therefore, the 
gender difference in the struggle to obtain autonomy or independence would be leveled out or at a minimal extent that would not be sufficient to influence a consequential difference between genders in the perception of family social support. However, further research is still needed for clarification of this proposal of the complications of independence issues in one's perceived support from family.

From the present results, there were also no significant gender differences found for self-esteem among male and female students, which means the third hypothesis was rejected. This is quite a great contrary to most researches which supported the hypothesis that there was a significant gender differences in self-esteem. Simmons and Rosenberg (1975, cited in Harter, 1990) reported that girls were found to have lower self-esteem than boys during their adolescence years. Gender differences in self-esteem have always shown that boys tend to exhibit higher self-esteem than girls did (O'Brien et al., 1996, cited in Quatman \& Watson, 2001). Demo et al., (1987, cited in Quatman \& Watson, 2001) found that male self-esteem was more strongly related to family relationships than was female self-esteem. As most of the researches were conducted in the western countries, cultural differences may play a role in contributing the insignificant difference outcome for this study. Higher self-esteem among Western male adolescents is expected as males are seen as the stronger, more able and emotionally stable as compared to female adolescents.

To conclude, it has always been debated whether self-esteem is a stable characteristic (Bachman \& O'Malley, 1977) or it fluctuated throughout one's life. Factors like parental marital status, family functioning and income level were all found to affect individual's self-esteem (Mandara, \& Murray, 2000). Mandura and Murray strongly supported the notion that female generally tend to have lower level of self-esteem as compared to male but the researchers have yet to come across studies which commenting on the opposing claim. The present study revealed that there were no gender differences in self-esteem and perceived social support. In this study, it was hypothesized that female would have higher level of perceived social support and lower level of self-esteem. Contrastingly, results showed that there were no significant differences between gender, perceived social support and self-esteem. Kendler, Gardner and Prescott (1998) found that gender differences in self-esteem are influenced by socialization experiences and environment factors besides genetic factors. We speculated that in the Malaysian context females have improved in assertiveness and socialization experiences. They also have been influenced by environmental factors such as working experiences, relationships with friends, co-workers and so on. Therefore, it is common nowadays to see Malaysian females playing an important role in high ranking personnel and the number of females attending tertiary education has increased tremendously. There was no significant gender difference in perceived social support in the present study which reflected that Malaysian families provided rather similar attention to daughters and sons. Similarly in the social relationships, the males and females in Malaysia were rather aggressive in obtaining reliance and intimacy through social networking. All these factors would help to explain why there were no gender differences in perceived social support and self-esteem in the Malaysian sample.

\section{Strengths and Limitations}

The number of participants in this study is fairly a large number; therefore, sufficient information can be obtained through this study. There is also some equality of races among the adolescents, therefore no biasness occurred in the study and the results are free of racial/cultural perceptions. The questionnaires were simple and straightforward because of the high construct validity and they have been used by previous researchers. The instruments were valid and have high reliability.

However, the findings of the present study must be interpreted in light of some limitations as well. Although the validity and reliability of the two scales were given based on studies by other researchers, there was no pilot test conducted to examine the constructiveness and validity towards local Malaysian adolescents. Besides, the 460 participants were selected from only 2 areas (Kuala Lumpur and Petaling Jaya) and therefore the findings cannot be generalized to all adolescents in Malaysia.

\section{Recommendations for Future Research}

Further research is needed to explore the more complex nature of the balance between support from adults (family) and peers, as each may provide different support functions that would alter the perception of perceived social support, which may lead to higher or lower self-esteem. A longitudinal study to measure changes in self-esteem from younger primary school children to older secondary school children would increase our understanding of what happens in early stage of adolescents and reasons on how they perceive social support. It would also be interesting to conduct this study between urban and rural areas as adolescents from the two different environments may lead to difference findings. The range of the age could be widened to cover a larger scope of different outcomes from different stages of adolescence. 


\section{Conclusion}

The present study revealed a significant positive correlation between perceived social support and self-esteem among adolescents. However, there were no significant differences for perceived social support and self-esteem among male and female respondents. Research uses adolescents as samples can provide insights to what individual experiences and predicting the contributing factors towards receiving support from family and peers at a certain period of time. The development of self-esteem is essential and broad research evidences found that the pursuit of an adolescent self-esteem can be obtained through the perceived social support of their surrounding environment. The implication of having moderate/high level of self-esteem is such adolescents would have higher tendency to rectify their behavioral mistakes using constructive strategies. As pointed by research evidences avoiding low self-esteem is essential as to lead happy and productive life style. All in all, review of research evidences showed that there was significant relationship between self-esteem and perceived social support, it is worth noted that support which include care, praise and nurturing from parents are essential and should be provided since young.

\section{References}

Ayyash-Abdo, H. (2003). Adolescants' self-image in Labanon: Implication for education in Pajares, F \& Urdan, T. (Ed). (2003). Adolescence and education: International perspectives on adolescence. United States: Information Age Publishing Inc. 173-198.

Bachman, J. G., \& O’Malley, P. M. (1977). Self-esteem in young men: A longitudinal analysis of the impact of educational and occupational attainment. Journal of Personality and Social Psychology, 35, 365-380.

Caldwell, M. A., \& Peplau, L. A. (1982). Sex differences in same-sex friendship. Sex Roles, 8(7), 721-732.

Cartwright, L.E. (2000). Selecting local sustainable development indicators: does consensus exist in their choice and purpose? Planning Practice \& Research, 15(1/2), 65-78.

Cheng, S. K., \& Fatimah, Y. (n.d.). Roles of Dysfunctional Attitudes and Self-esteem in the Relationship between Social Support and Depression in Late Adolescence. Proceedings of the WSEAS International Conferences on Sociology, Psychology, Philosophy.

Chubb, N. H., Fertman, C. I., \& Ross, J. L. (1997). Adolescent self-esteem and locus of control: A longitudinal study of gender and age differences. Journal of Adolescence, 32, 113-129.

Chun, Y.J. \& MacDermid, S. M. (1997). Perceptions of family differentiation, individuation, and self-esteem among Korean adolescents. Journal of Marriage and the Family, 59, 451-462.

Cohen, S. \& Wills, T. A. (1985). Stress, social support, and the buffering hypothesis. Psychological Bulletin, 98, 310-357.

Colarossi, 1. G., \& Eccles, J. S. (2000). A prospective study of adolescents' peer support: Gender differences and the influence of parental relationship. Journal of Youth and Adolescence, 29(6), 661.

Colarossi, L. G. (2001). Adolescent gender differences in social support: Structure, function, and provider type. Social Work Research, 25(4), 233.

Corwyn, R.F., \& Benda, B. B. (2001). Violent youths in southern public schools in America. International Journal Adolescent Youth Spec Violent Youth, 10, 69-90.

Dollete, M., Steese, S., Philips, W. \& Matthews, G. (2006). Understanding girls' circle as an intervention on perceived social support, body image, self-efficacy, locus of control and self-esteem. Girls' Circle Association : A Project of The Tides Center.

Dumont, M, Provost, A.M. (1999). Resilience in adolescents: Protective role of social support, coping strategies, self-esteem, and social activities on experience of stress and depression. Journal of Youth and Adolescence, 20(3), 343

Farmer, T. W., \& Farmer, E. M. (1996). The social relationships of students with exceptionalities in mainstream classrooms: Social network centrality and homophily. Exceptional Children, 62, 431-450.

Feshbach, S., \& Weiner, B. (1991). Personality. Toronto, Ontario, Canada: D.C. Heath.

Fischer, A.R., Shaw, C.M. (1999). African Americans' Mental Health and Perceptions of Racist Discrimination: The Moderating Effects of Racial Socialization Experiences and Self-Esteem. Journal of Counseling psychology, 46 (3), 395-407.

Frechette, M., \& Leblane, M (1987). Delinquances et delinquants. Chicoutimi, Quebec: Gaetan Morin. 
Geuzaine, C., Debry, M., \& Leissen, V. (2000). Separation from parents in late adolescence: The same for boys and girls? Journal of Youth and Adolescence, 29, 79-91.

Harter, S. (1990). Identity and self development. In S. Feldman and G. Elliott (Eds.). At the threshold: The developing adolescent (pp. 352-387). Cambridge, MA: Harvard University Press.

Herman-Stahl, M., \& Pertersen, A. C. (1996). A protective role of coping and social resources for depressive symptoms among young adolescents. Journal of Youth and Adolescence, 25, 733-753.

Hirsch, B., \& DuBois, D. (1991). Self-esteem in early adolescence: The identification and prediction of contrasting longitudinal trajectories. Journal of Youth and Adolescence, 20, 53-72.

Hollister-Wagner, G. H., Foshee, V.A., \& Jackson, C. (2001). Adolescent aggression: models of resiliency. Journal of Applied Social Psychology, 32, 445-466.

Huurre, T. (2000). Psychosocial development and social support among adolescents with visual impairment, Academic Dissertation, University of Tampere, 20-52.

Kaplan, H. B. (1980). Deviant Behavior and Self-Enhancement in Adolescence. Journal of Youth and Adolescence, 7, 253-277.

Kendler, K. S., Gardner, C. O., \& Prescott, C. A. (1998). A population-based twin study of self-esteem and gender. Psychological Medicine, 28, 1403-1409.

Lee. C.L., Chen.C.Y,, Lee. K.K., \& Kaur.J. (2007). Violence-Related Behaviours among Malaysian Adolescents: A Cross Sectional Survey among Secondary School Students in Negeri Sembilan. Annals Academy of Medicine, 36(3), 169-174.

Lipschitz-Elhawi, R. \& Ltzhaky, H. (2005). Social Support, Mastery, Self-esteem and Individual Adjustment among At-Risk Youth. Child \& Youth Care Forum, 34(5).

Mahaffy, K. A. (2004). Girls' Low Self-Esteem: How Is It Related to Later socioeconomic Achievements?. Gender and Society, 18(3): 309-327.

Mandara, J., \& Murray, C. B. (2000). Effects of parental marital status, income, and family functioning on African American adolescent self-esteem. Journal of Family Psychology, 14, 475-490.

Mizell, C. A. (1999). African American men's personal sense of mastery: The consequences of the adolescent environment, self-concept, and adult achievement. Journal of Black Psychology, 25, 210-230.

Moradi, B. \& Funderbunk, J.R. (2006). Roles of perceived sexist events and perceived social support in the mental health of women seeking counseling. Journal of Counseling Psychology, 53(4), 464-473.

Nugent, W.R., \& Thomas, J.W. (1992). Validation of the self-esteem rating scale. Research on Social Work Practice, 3, 191-207.

Parker, J. G. \& Asher, S. R. (1987). Peer relations and later personal adjustment: Are low-accepted children at risk? Psychological Bulletin, 102, 357-389.

Quatman, T., \& Watson, C. M. (2001). Gender differences in adolescent self-esteem: An exploration of domains. The Journal of Genetic Psychology, 162(1), 93-117.

Riecken, G., Yavas, U. (2001). Improving quality of life in a region: a survey of area residents and public sector implications. The International Journal of Public Sector Management, 14, 556-568.

Teoh, H. J. \& Nur Afiqah, R. (2010). Self-esteem Amongst Young Adults: The Effect of Gender, Social Support and Personality. MJP Online Early.

The Royal Malaysian Police. (2004).

Wolchik, S. A., Reuhlman, L. S., Braver, S. L. \& Sandler, I. N. (1989). Social support of children of divorce: Direct and stress buffering effects. American Journal of Community Psychology, 17, 485-501.

Zimet, G. D., Dahlem, N. W., Zimet, S. G., \& Farley, G. K. (1988). The multidimensional scale of perceived social support. Personality Assess, 52(1): 30-41. 
Table 1. Correlation Depicting Relationship between Perceived Social Support and Self-Esteem

\begin{tabular}{|c|c|c|c|}
\hline \multicolumn{4}{|c|}{ Self-Esteem } \\
\hline Perceived Social Support & \multicolumn{3}{|c|}{$.498(* *)$} \\
\hline \multicolumn{4}{|l|}{$* *$ Significant at $\mathrm{p}<.01$} \\
\hline \multicolumn{4}{|c|}{ Table 2. Correlation Depicting Relationship between Subscales of Perceived Social Support and Self-Esteer } \\
\hline \multicolumn{4}{|c|}{ Perceived Social Support } \\
\hline & Significant Other & Family & Friends \\
\hline Self-Esteem & $.367(* *)$ & $.378(* *)$ & $.413(* *)$ \\
\hline
\end{tabular}

$* *$ Significant at $\mathrm{p}<.01$

Table 3. Mean Scores and Standard Deviations for Measures of Perceived Social Support and Self-Esteem

\begin{tabular}{lcccc}
\hline & \multicolumn{2}{c}{ Male } & \multicolumn{2}{c}{ Female } \\
& $\mathrm{M}$ & $\mathrm{SD}$ & $\mathrm{M}$ & $\mathrm{SD}$ \\
\hline Self-Esteem & 192.12 & 34.214 & 191.162 & 31.744 \\
Perceived Social Support & 61.47 & 11.286 & 62.71 & 11.854 \\
\hline
\end{tabular}

$* \mathrm{p}<.05$ 